\title{
Controle de Urochloa plantaginea com herbicidas residuais e performance agronômica de dois cultivares de feijoeiro ${ }^{1}$
}

\section{Urochloa plantaginea control with residual herbicides and the crop agronomic}

\author{
performance of two bean cultivars
}

\author{
Augusto Kalsing ${ }^{2}$; Ribas Antônio Vidal ${ }^{3}$
}

\begin{abstract}
Resumo - O objetivo deste trabalho foi avaliar os efeitos da utilização de herbicidas residuais, aplicados em pré-emergência do feijoeiro, sobre a redução da infestação de plantas daninhas e o desempenho agronômico da cultura. Foram realizados dois experimentos a campo, sendo que um tinha o cultivar UFT -06 (Grupo Carioca, ciclo curto e porte ereto) e o outro o cultivar IPR Graúna (Grupo Preto, ciclo longo, hábito prostrado). Os tratamentos foram constituídos da aplicação dos herbicidas pendimethalin $\left(1,2 \mathrm{e} 1,4 \mathrm{~kg} \mathrm{ha}^{-1}\right)$ e trifluralin $\left(1,2 \mathrm{e} 1,4 \mathrm{~kg} \mathrm{ha}^{-1}\right)$; e, dimethenamid $(1,4 \mathrm{e}$ $1,6 \mathrm{~kg} \mathrm{ha}^{-1}$ ) e S-metolachlor (1,4 e 1,6 $\left.\mathrm{kg} \mathrm{ha}^{-1}\right)$, e mais testemunha com e sem (TSC) controle. Nas áreas experimentais predominavam infestação de Urochloa plantaginea (papuã). Avaliou-se a densidade e a massa desta espécie daninha, e o número de legumes e a produtividade do feijoeiro. Trifluralin foi o herbicida que mais reduziu a infestação da planta daninha e aumentou o rendimento do feijoeiro, quando comparado aos demais produtos. O cv. de feijão UTF-06 foi mais competitivo com U. plantaginea do que IPR Graúna. Os tratamentos com herbicida reduziram a infestação da infestante, mas isso não resultou em maior produtividade do feijoeiro, quando comparado com o tratamento capinado.
\end{abstract}

Palavras-chaves: Brachiaria plantaginea, competição, interferência, manejo integrado

\begin{abstract}
The objective of this study was to evaluate the effects of the use of residual herbicides applied in the pre-emergence of beans, on reducing weed infestations, and the agronomic performance of the crop. Two field experiments were conducted, one had the cultivar UFT -06 (Carioca Group, short cycle and erect) and another, the IPR Graúna (Black Group, long cycle, prostrate habit). The treatments consisted of application of the herbicides pendimethalin (1.2 and $\left.1.4 \mathrm{~kg} \mathrm{ha}^{-1}\right)$ and trifluralin $\left(1.2\right.$ and $\left.1.4 \mathrm{~kg} \mathrm{ha}^{-1}\right)$; and dimethenamid $\left(1.4\right.$ and $\left.1.6 \mathrm{~kg} \mathrm{ha}^{-1}\right)$ and $\mathrm{S}$ metolachlor (1.4 and $\left.1.6 \mathrm{~kg} \mathrm{ha}^{-1}\right)$, and weedy and weed-free checks for comparison. In the experimental areas, Urochloa plantaginea (Alexander grass) infestation predominated. It was evaluated the density and the biomass of this weed, and the number of pods and yield of the bean. Trifluralin was the herbicide that most reduced the infestation of the weeds and increased the yield of the bean, when compared to the other products. The UTF-06 bean cv. was more competitive with $U$. plantaginea than IPR Graúna. The treatments with herbicide reduced the infestation of weed, but this did not result in higher yields of bean, compared to the weed-free treatment.
\end{abstract}

Keywords: Brachiaria plantaginea, competition, interference, integrated management

\footnotetext{
${ }^{1}$ Recebido para publicação em 11/04/2014 e aceito em 15/07/2015.

${ }^{2}$ Eng. Agr., M. Sc., Crop Protection R\&D, Dow AgroSciences Industrial Ltda. Av. Nações Unidas, 14.171 - São

Paulo, SP, Brasil.<Akalsing@dow.com>

${ }^{3}$ Eng. Agr., Ph. D., Universidade Federal do Rio Grande do Sul - UFRGS. Av. Bento Gonçalves, 7712, Porto

Alegre, RS, Brasil.<ribas.vidal@gmail.com>
} 


\section{Introdução}

Na última década, o cultivo de feijão no Brasil abrangeu uma área anual de aproximadamente quatro milhões de hectares, na qual se produziu cerca de três milhões de toneladas de grãos (IBGE, 2015). Neste período a produtividade média desta cultura foi inferior a $1.000 \mathrm{~kg} / \mathrm{ha}$, embora nas lavouras com elevado nível de manejo sejam obtidos valores três vezes superiores. Muitas causas são aventadas para esta situação, dentre as quais se destaca o impacto negativo das plantas daninhas à cultura (Cobucci, 2008). De fato, o feijoeiro tem sido em grande parte cultivado por agricultores com baixa tecnologia de produção, onde a gestão dessas espécies nem sempre ocorre no momento ou intensidade adequadas. Deste modo, estimase que dentre todos os cultivos anuais praticados no Brasil, o feijão tem sido aquele que tem uma das maiores perdas causadas pela interferência das plantas daninhas (Cobucci, 2008).

O manejo integrado (MIPd) é uma das principais estratégias para otimizar o controle de plantas daninhas e racionalizar a utilização de herbicidas no agroecossistema (Nunes et al., 2010). Embora seja difundido e utilizado em diversas culturas anuais, como arroz irrigado, soja e milho, o MIPd é pouco explorado no caso da cultura do feijão (Blackshaw et al., 2000). De fato, os programas de manejo nessa cultura baseiam-se em capinas manuais ou no uso de herbicidas de aplicação em pós-emergência, de acordo com o nível tecnológico empregado na lavoura. Ambas as medidas de controle nem sempre propiciam controle duradouro quando usadas de forma isolada, devido à re-infestação da área com novo fluxo de emergência de plantas daninhas.

Dentre as estratégias de MIPd propostas para otimizar a eficácia do controle de plantas daninhas no feijoeiro, incluem-se a integração de práticas agrícolas e o emprego criterioso de herbicidas. Por exemplo, as características morfofisiológicas dos cultivares podem modificar as relações de interferência entre culturas e as plantas daninhas (Cobucci,
2008; Vidal et al., 2010). Plantas de feijão de porte prostrado e semi-ereto conferem maior habilidade competitiva à cultura com comunidades de plantas daninhas (Teixeira et al., 2009; Barroso et al., 2010). Outro exemplo de estratégia que contribui para reduzir a infestação e a interferência de plantas daninhas no feijoeiro é a utilização de herbicidas que possuem atividade residual no solo. O uso de herbicidas residuais pode ser muito oportuno em programas de MIPd em feijão, reduzindo em até 90\% a infestação dessas espécies (Soltani et al., 2010; Kalsing e Vidal, 2012).

O objetivo deste trabalho foi o de avaliar os efeitos do uso associado de diferentes cultivares de feijão e herbicidas residuais, aplicados na condição de pré-emergência, sobre a infestação de plantas daninhas e a produtividade do feijoeiro.

\section{Material e Métodos}

$\mathrm{Na}$ safra 2008/09 foram realizados dois experimentos a campo no município de Eldorado do Sul, RS. O solo da área experimental foi classificado como Argissolo vermelho distrófico (Streck et al., 2008), e teve, na análise laboratorial, $28 \%$ de argila, $1,5 \%$ de matéria orgânica e pH igual a 6,0. A área vem sendo cultivada há mais de 20 anos durante a estação de crescimento estival com soja ou milho, e tem elevado nível de infestação com plantas daninhas de ciclo anual.

Cada experimento continha um dos seguintes cultivares de feijão: IPR Graúna (Grupo Preto, porte ereto) e UFT-06 (Grupo Carioca, porte semi-ereto), mas a lista de tratamentos era idêntica em ambos para possibilitar a análise conjunta dos dados (Nogueira, 1997). O delineamento experimental utilizado foi o de blocos completamente casualizados, com tratamentos em esquema fatorial e quatro repetições para cada tratamento. Um fator foi constituído de quatro herbicidas residuais aplicados em préemergência, e outro fator correspondeu a duas 
doses para cada herbicida com atividade residual, a saber: 2,0 e $2,4 \mathrm{~kg} \mathrm{ha}^{-1}$ de pendimethalin (Herbadox, $400 \quad \mathrm{~g} \quad \mathrm{~L}^{-1}$ ) $\mathrm{e}$ trifluralin (Premerlin, $600 \mathrm{~g} \mathrm{~L}^{-1}$ ); e, 1,2 e 1,4 kg $\mathrm{ha}^{-1}$ de S-metolachlor (Dual Gold, $915 \mathrm{~g} \mathrm{~L}^{-1}$ ) e dimethenamid (Zeta, $900 \mathrm{~g} \quad \mathrm{~L}^{-1}$ ), sendo adicionadas testemunhas com (TCC) e sem controle (TSC). As doses de pendimethalin, trifluralin e S-metolachlor situam-se na faixa de doses registradas para a cultura do feijão, enquanto as doses de dimethenamid foram definidas com base no registro para a cultura da soja (MAPA, 2014).

Os tratamentos foram aspergidos logo após a semeadura do feijoeiro, utilizando-se pulverizador costal de precisão à pressão constante, com volume de calda correspondente a 180 1/ha. As aplicações foram feitas em momento com temperatura do ar $\left(18{ }^{\circ} \mathrm{C}\right)$, umidade do ar (81\%) e umidade volumétrica do solo $(22 \%)$ adequadas para o uso de herbicidas aplicados ao solo.

Anteriormente à semeadura do feijoeiro foram realizadas duas gradagens do solo. Dez sementes de feijão por metro linear foram distribuídas nas fileiras espaçadas em $0,4 \mathrm{~m}$, perfazendo-se uma população de 250.000 plantas ha-1 ${ }^{-1}$ A adubação do solo foi feita pela distribuição nas linhas de semeadura de $400 \mathrm{~kg}$ $\mathrm{ha}^{-1}$ da fórmula 05-20-30 (N-P-K), aportando $20 \mathrm{~kg} \mathrm{ha}^{-1}$ de N, $80 \mathrm{~kg} \mathrm{ha}^{-1} \mathrm{de}_{2} \mathrm{P}_{5}$ e $120 \mathrm{~kg} \mathrm{ha}^{-}$ ${ }^{1}$ de $\mathrm{K}_{2} \mathrm{O}$. Posteriormente, realizaram-se mais duas adubações com $30 \mathrm{~kg} \mathrm{ha}^{-1}$ de $\mathrm{N}$ e $15 \mathrm{~kg} \mathrm{ha}^{-}$ ${ }^{1}$ de $\mathrm{K}_{2} \mathrm{O}$ quando as plantas de feijão atingiram os estádios $\mathrm{V}_{3}$ e $\mathrm{V}_{5}$ (Gepts e Fernandez, 1982). $\mathrm{O}$ manejo de insetos e doenças foi sempre realizado quimicamente e preventivamente, com produtos registrados para a cultura do feijão.

Os feijoeiros estavam infestados de forma homogênea e predominante pela espécie Urochloa plantaginea (Link) R.D. Webster (papuã). As poucas espécies dicotiledôneas foram controladas com bentazon (Basagran, 600 $\mathrm{g} \mathrm{L}^{-1}$ ) à $0,6 \mathrm{~kg} \mathrm{ha}^{-1}$, imediatamente após a realização da primeira adubação do solo em cobertura. As unidades experimentais corresponderam a parcelas com área de $20 \mathrm{~m}^{2}$, nas quais foram aspergidos, de forma totalmente aleatória, os tratamentos com herbicidas residuais e doses.

Aos 20 e 40 dias após a emergência (DAE) do feijão avaliaram-se a densidade e a massa fresca da parte aérea de U. plantaginea, sendo os valores obtidos convertidos para plantas $\mathrm{m}^{-2}$ e $\mathrm{g} \mathrm{m}^{-2}$, respectivamente. Ao final, com a maturação dos grãos, avaliaram-se o número de legumes $\mathrm{m}^{-2} \mathrm{e}$ a produtividade de grãos, sendo no último caso os valores convertidos para $\mathrm{kg} \mathrm{ha}^{-1} \mathrm{e}$ expressos na umidade de $13 \%$.

Primeiramente, os dados da densidade e massa fresca da parte aérea foram ponderados em relação ao valor da TSC de U. plantaginea, a fim de normalizar os efeitos dos tratamentos herbicidas em escala percentual. Na sequência, compararam-se os erros experimentais dos dois experimentos (cultivares), sendo constatada a possibilidade de análise conjunta dos experimentos e fatores (Campos, 1984; Nogueira, 1997). Os dados foram submetidos à análise de variância pelo teste $\mathrm{F}$ de forma conjunta, usando-se nível de $5 \%$ de probabilidade do erro experimental como limite para detecção de significância. Por fim, as médias dos tratamentos foram comparadas pela diferença mínima significativa (DMS), calculada pelo teste $t$ de Student com o mesmo limite de detecção de significância supracitado. Também se realizaram comparações das médias das TSC e TCC com cada uma das médias dos tratamentos utilizando-se a DMS.

\section{Resultados e Discussão}

A análise conjunta dos experimentos evidenciou que a densidade de $U$. plantaginea foi dependente da interação entre 'experimentos' e 'herbicidas', tanto no início como no final do período crítico de interferência na cultura. Não houve efeito de dose dos herbicidas (Tabela 1). O cultivar UTF06 foi mais competitivo com a infestante e causou maior redução da densidade da planta 
daninha do que IPR Graúna, apresentando superioridade na maioria das situações nas duas avaliações. $\mathrm{O}$ herbicida trifluralin foi $\mathrm{o}$ mais eficaz na redução na densidade populacional de U. plantaginea, tendo a magnitude do seu efeito variado entre nove e $23 \%$ em relação à TSC.
Dimethenamid geralmente teve os menores valores de redução da magnitude desta variável, os quais só foram estatisticamente distintos aos dos outros herbicidas em 50\% dos casos (Tabela $1)$.

Tabela 1. Densidade de Urochloa plantaginea na cultura do feijão em função de dois cultivares de feijão e de quatro herbicidas residuais, na média de duas doses e em duas épocas de avaliação. Eldorado do Sul, RS, 2008/09.

\begin{tabular}{|c|c|c|c|c|}
\hline \multirow{3}{*}{ Tratamentos } & \multicolumn{4}{|c|}{ Densidade de plantas $(\%)^{(1)}$} \\
\hline & \multicolumn{2}{|c|}{$20 \mathrm{DAE}^{(2)}$} & \multicolumn{2}{|c|}{$40 \mathrm{DAE}$} \\
\hline & IPR Graúna & UTF-06 & IPR Graúna & UTF-06 \\
\hline Dimethenamid & $56 \mathrm{aA}^{(3)}$ & $22 \mathrm{bB}$ & $87 \mathrm{aA}$ & $37 \mathrm{bAB}$ \\
\hline S-metolachlor & $41 \mathrm{aB}$ & $18 \mathrm{bB}$ & $54 \mathrm{aB}$ & $30 \mathrm{bB}$ \\
\hline Pendimethalin & $25 \mathrm{bC}$ & $37 \mathrm{aA}$ & $32 \mathrm{bC}$ & $46 \mathrm{aA}$ \\
\hline Trifluralin & $13 \mathrm{aD}$ & $9 \mathrm{aC}$ & $23 \mathrm{aC}$ & $13 \mathrm{bC}$ \\
\hline C. V. ${ }^{(4)}(\%)$ & \multicolumn{2}{|c|}{38} & \multicolumn{2}{|c|}{40} \\
\hline $\operatorname{DMS}^{(5)}(\mathrm{A})(5 \%)$ & \multicolumn{2}{|c|}{5} & \multicolumn{2}{|c|}{5} \\
\hline DMS (B) $(5 \%)$ & \multicolumn{2}{|c|}{8} & \multicolumn{2}{|c|}{11} \\
\hline DMS (C) $(5 \%)$ & \multicolumn{2}{|c|}{15} & \multicolumn{2}{|c|}{23} \\
\hline \multicolumn{5}{|c|}{$\begin{array}{l}\text { (1) Valor percentual em relação à situação com ausência de controle de } U \text {. plantaginea. A saber, aos } 20 \text { DAE: } 845,5 \\
\text { plantas } \mathrm{m}^{-2} \text {; e, aos } 40 \text { DAE: } 754,2 \text { plantas } \mathrm{m}^{-2} .^{(2)} \text { Dias após a emergência da cultura. As avaliações realizadas aos } 20 \mathrm{e} \\
40 \text { DAE corresponderam aos estádios } \mathrm{V}_{3} \mathrm{e}_{5} \text { do feijoeiro, respectivamente. }{ }^{(3)} \text { Médias com letras distintas diferem } \\
\text { entre si pelo teste } \mathrm{t}(\mathrm{p}<0,05) \text {, sendo que letras minúsculas comparam médias na horizontal e letras maiúsculas } \\
\text { comparam médias na vertical. }{ }^{(4)} \text { Coeficiente de variação. }{ }^{(5)} \text { Diferença mínima significativa para comparar valores } \\
\text { médios de: (A) cultivares em um mesmo herbicida; (B) herbicidas em um mesmo cultivar; e (C) quaisquer cultivares } \\
\text { e (ou) herbicidas. }\end{array}$} \\
\hline
\end{tabular}

Para a massa fresca de U. plantaginea, também detectou-se interação significativa entre 'experimentos (cultivares)' e 'herbicidas', em ambas as datas de avaliação do nível de infestação da cultura do feijão. Não houve efeito de dose dos herbicidas (Tabela 2). Comparandose os dois cultivares no mesmo herbicida, verificou-se que UTF-06 inibiu mais o crescimento da infestante do que IPR Graúna em três das quatro comparações possíveis. Todos os herbicidas residuais avaliados no trabalho reduziram o acúmulo de massa fresca de $U$. plantaginea, sendo trifluralin àquele que teve melhor desempenho na maioria das situações. Mas, destaca-se que nem sempre se observou diferenciação significativa entre os efeitos obtidos com os quatro herbicidas residuais sobre a magnitude dessa variável explicativa da infestante. A análise conjunta dos experimentos para as variáveis que envolveram a resposta da cultura evidenciou a interação de todos os fatores testados. Assim, o número de legumes $/ \mathrm{m}^{2}$ de feijão variou em função da interação significativa entre 'experimentos (cultivares)', 'herbicidas' e 'doses', e teve alta amplitude de variação, situando-se entre 50 e 250 legumes $\mathrm{m}^{-2}$ (Tabela 3 ).

As plantas da TCC produziram $250 \mathrm{e}$ 244 legumes $\mathrm{m}^{-2}$, enquanto que as plantas da TSC apresentaram apenas 110 e 50 legumes $\mathrm{m}^{-}$ 2 , respectivamente, para os cultivares IPR Graúna e UTF-06. Com isso, houve redução no valor desta variável de até $58 \%$ em IPR Graúna e $80 \%$ em UTF-06. Constatou-se maior número de legumes $/ \mathrm{m}^{2}$ na TCC do que nas parcelas com herbicidas residuais. As plantas das parcelas 
tratadas com herbicidas tiveram mais legumes $/ \mathrm{m}^{2}$ do que a TSC em cinco casos, dos oito possíveis, na cultivar IPR Graúna; e, em sete casos, em UTF-06. Trifluralin foi $o$

herbicida que propiciou maior incremento do número legumes $/ \mathrm{m}^{2}$ em relação à TSC; mas, nem sempre seu efeito foi estatisticamente superior ao dos demais produtos avaliados.

Tabela 2. Massa fresca da parte aérea de Urochloa plantaginea na cultura do feijão em função de dois cultivares de feijão e de quatro herbicidas residuais, na média de duas doses e em duas épocas de avaliação. Eldorado do Sul, RS, 2008/09.

\begin{tabular}{|c|c|c|c|c|}
\hline \multirow{3}{*}{ Tratamentos } & \multicolumn{4}{|c|}{ Massa fresca da parte aérea $(\%)^{(1)}$} \\
\hline & \multicolumn{2}{|c|}{$20 \mathrm{DAE}^{(2)}$} & \multicolumn{2}{|c|}{$40 \mathrm{DAE}$} \\
\hline & IPR Graúna & UTF-06 & IPR Graúna & UTF-06 \\
\hline Dimethenamid & $33 \mathrm{aA}^{(3)}$ & $15 \mathrm{bB}$ & $88 \mathrm{aA}$ & $45 \mathrm{bB}$ \\
\hline S-metolachlor & $23 \mathrm{aA}$ & $9 \mathrm{bB}$ & $58 \mathrm{aB}$ & $41 \mathrm{bB}$ \\
\hline Pendimethalin & $24 \mathrm{bA}$ & $45 \mathrm{aA}$ & $41 \mathrm{bC}$ & $65 \mathrm{aA}$ \\
\hline Trifluralin & $8 \mathrm{aB}$ & $7 \mathrm{aB}$ & $29 \mathrm{aD}$ & $28 \mathrm{aC}$ \\
\hline C. V. ${ }^{(4)}(\%)$ & \multicolumn{2}{|c|}{68} & \multicolumn{2}{|c|}{22} \\
\hline $\operatorname{DMS}^{(5)}(\mathrm{A})(5 \%)$ & \multicolumn{2}{|c|}{7} & \multicolumn{2}{|c|}{5} \\
\hline $\operatorname{DMS}(\mathrm{B})(5 \%)$ & \multicolumn{2}{|c|}{10} & \multicolumn{2}{|c|}{8} \\
\hline DMS (C) $(5 \%)$ & \multicolumn{2}{|c|}{20} & \multicolumn{2}{|c|}{15} \\
\hline
\end{tabular}

(1) Valor percentual em relação à situação com ausência de controle de $U$. plantaginea. A saber, aos 20 DAE: 69,7 g $\mathrm{m}^{-2}$; e, aos 40 DAE: $253,5 \mathrm{~g} \mathrm{~m}^{-2}$. (2) Dias após a emergência da cultura. As avaliações realizadas aos 20 e 40 DAE corresponderam aos estádios $\mathrm{V}_{3} \mathrm{e} \mathrm{V}_{5}$ do feijoeiro, respectivamente. ${ }^{(3)}$ Médias com letras distintas diferem entre si pelo teste $\mathrm{t}(\mathrm{p}<0,05)$, sendo que letras minúsculas comparam médias na horizontal e letras maiúsculas comparam médias na vertical. ${ }^{(4)}$ Coeficiente de variação do conjunto de dados obtido na análise de variância. ${ }^{(5)}$ Diferença mínima significativa para comparar valores médios de: (A) cultivares em um mesmo herbicida; (B) herbicidas em um mesmo cultivar; e (C) quaisquer cultivares e (ou) herbicidas.

Para o rendimento de grãos de feijão, detectou-se interação significativa entre 'experimentos (cultivares)', 'herbicidas' e 'doses' (Tabela 4). Esta variável explicativa teve grande amplitude, com valores situados de 100 a $2.600 \mathrm{~kg} \mathrm{ha}^{-1}$. Obteve-se produção de 2.600 e $1.700 \mathrm{~kg} \mathrm{ha}^{-1}$ na TCC, enquanto que, na TSC, produziu-se somente 380 e $100 \mathrm{~kg} \mathrm{ha}^{-1}$, para os cultivares de feijão IPR Graúna e UTF06, respectivamente. Verifica-se, assim, redução desta variável de até $88 \%$ em IPR Graúna e 96\% em UFT-06.

Constatou-se maior rendimento de grãos na TCC em relação às áreas tratadas com herbicidas, todavia, estes produtos incrementaram a produtividade do feijoeiro em relação à TSC. De fato, constatou-se superioridade estatística da produtividade da cultura nas áreas tratadas sobre a TSC em seis casos, dos oito possíveis, para os dois cultivares de feijão ora analisados. Entre os herbicidas, trifluralin propiciou os maiores aumentos no rendimento de grãos em relação à situação com infestação, de forma análoga ao ocorrido para o número de legumes $\mathrm{m}^{-2}$ (Tabela 4).

Uma das hipóteses deste trabalho era de que as características morfisiológicas dos cultivares de feijão poderiam influenciar a magnitude da infestação e da interferência de plantas daninhas no feijoeiro. De fato, os dois cultivares tiveram diferenciação quanto à competitividade com $U$. plantaginea, havendo geralmente superioridade de UTF-06 em relação à IPR Graúna (Tabelas 1 e 2). Estes resultados são similares àqueles observados por Andrade et al. (1999) e Teixeira et al. (2009), que relatam competição diferencial de genótipos de feijão com plantas daninhas. Segundo esses autores, características como arquitetura da planta, ciclo de desenvolvimento, hábito de crescimento e 
número de ramos modificam a habilidade competitiva do feijoeiro. Os resultados desses e do presente estudo confirmam que a escolha de cultivares de feijão altamente competitivas constitui-se em um fator decisivo para o sucesso do MIPd no feijoeiro.

Tabela 3. Número de legumes por área da cultura do feijão em função do efeito de dois cultivares de feijão, quatro herbicidas residuais e duas doses. Eldorado do Sul, RS, 2008/09.

\begin{tabular}{|c|c|c|c|c|}
\hline \multirow{3}{*}{ Tratamentos } & \multicolumn{4}{|c|}{ Legumes por área $\left(\mathrm{n}^{\circ} \mathrm{m}^{-2}\right)$} \\
\hline & \multicolumn{2}{|c|}{ IPR Graúna } & \multicolumn{2}{|c|}{ UTF-06 } \\
\hline & Dose $100 \%$ & Dose $120 \%$ & Dose $100 \%$ & Dose $120 \%$ \\
\hline Dimethenamid & $\mathrm{R}^{*} 110,1 \mathrm{aC}(1)$ & $\mathrm{U}^{*} 103,7 \mathrm{aB}$ & $\mathrm{R}^{*} 130,5^{*} \mathrm{bC}$ & $\mathrm{T}^{*} 144,9^{*} \mathrm{aB}$ \\
\hline S-metolachlor & $\mathrm{R}^{*} 122,8 \mathrm{bBC}$ & $\mathrm{T}^{*} 160,7^{*}$ aA & $\mathrm{R}^{*} 152,4^{*} \mathrm{bB}$ & $\mathrm{T}^{*} 170,1^{*} \mathrm{aA}$ \\
\hline Pendimethalin & $\mathrm{R}^{*} 131,8^{*} \mathrm{bB}$ & $\mathrm{T} * 172,8^{*}$ aA & $S * 101,1^{*} \mathrm{aD}$ & $\mathrm{U}{ }^{*} 81,4 \mathrm{bC}$ \\
\hline Trifluralin & $\mathrm{R}{ }^{*} 187,1^{*} \mathrm{aA}$ & $\mathrm{T}^{*} 172,5^{*} \mathrm{bA}$ & $\mathrm{R}^{*} 180,1^{*} \mathrm{aA}$ & $\mathrm{T}^{*} 174,1^{*} \mathrm{aA}$ \\
\hline Test. sem controle & \multicolumn{2}{|c|}{$* 105,8$} & \multicolumn{2}{|c|}{$* 50,6$} \\
\hline Test. com controle & \multicolumn{2}{|c|}{$250,3 *(2)$} & \multicolumn{2}{|c|}{$244,3^{*}$} \\
\hline C. V. ${ }^{(3)}(\%)$ & \multicolumn{4}{|c|}{11,8} \\
\hline$\overline{\mathrm{DMS}^{(4)}(\mathrm{A})(\%)}$ & \multicolumn{4}{|c|}{10,1} \\
\hline DMS (B) (\%) & \multicolumn{4}{|c|}{14,3} \\
\hline DMS (C) (\%) & \multicolumn{4}{|c|}{20,2} \\
\hline DMS (D) (\%) & \multicolumn{4}{|c|}{28,6} \\
\hline DMS (E) $(\%)$ & \multicolumn{2}{|c|}{23,1} & \multicolumn{2}{|c|}{31,1} \\
\hline
\end{tabular}

(1) Médias com letras distintas diferem entre si pelo teste $t(p<0,05)$, sendo que letras minúsculas a direita $(a, b)$ comparam médias de doses de um mesmo herbicida, em uma mesma cultivar; letras maiúsculas a direita (A, B, C) comparam médias de herbicidas em uma mesma dose, em uma mesma cultivar; e, letras maiúsculas a esquerda (R, $\mathrm{S}$ e T, U) comparam médias de herbicidas em uma mesma dose, em cultivares diferentes. ${ }^{(2)}$ Asterisco ao lado direito dos valores significa diferença significativa $(p<0,05)$ em relação à testemunha sem controle e asterisco ao lado esquerdo indica diferença significativa $(\mathrm{p}<0,05)$ em relação à testemunha com controle. ${ }^{(3)}$ Coeficiente de variação do conjunto de dados obtido na análise de variância. ${ }^{(4)}$ Diferença mínima significativa para comparar médias de: (A) doses de um mesmo herbicida, num mesmo cultivar; (B) herbicidas em uma mesma dose, num mesmo cultivar; (C) doses de um herbicida em cultivares diferentes; (D) quaisquer cultivares, herbicidas e doses; e, (E) herbicidas em uma mesma dose com as testemunhas sem ou com controle, num mesmo cultivar.

Existem, pelo menos, duas diferentes explicações para se especular porque a cultivar UTF-06 foi melhor competidora do que a cv. IPR Graúna. Primeiro, o ciclo de UTF-06 é mais curto (75-80 dias) do que Graúna (85-90 dias) e, assim o primeiro cv. teria crescimento e sombreamento do terreno mais rápido do que o segundo. A segunda razão da elevada competitividade da UTF-06 é seu porte ereto que também a favorece no sombreamento rápido do terreno.

Outra hipótese deste trabalho era de que a utilização de herbicidas residuais na condição de pré-emergência do feijão reduziria a infestação com plantas daninhas durante o período crítico de interferência. Com efeito, os herbicidas dimethenamid, S-metolachlor, pendimethalin e trifluralin diminuíram a infestação de $U$. plantaginea, em relação à situação sem controle desta infestante (Tabelas 1 e 2). Além disso, houve incremento considerável do desempenho agronômico da cultura do feijão, expresso pelo rendimento de grãos e número de legumes m-2 (Tabelas 3 e 4). Estes resultados confirmam que herbicidas residuais aplicados em pré-emergência da cultura do feijão reduzem a densidade de plantas de plantas daninhas no período crítico de interferência. Vale ressaltar que estes resultados são advindos da análise conjunta de dois experimentos realizados a campo, o que 
imprime maior segurança para a validade da hipótese supracitada.

Em estudo similar, os herbicidas metolachlor, pendimethalin e trifluralin, nas doses de 2,5; 2,5 e 3,5 $\mathrm{kg} \mathrm{ha}^{-1}$, respectivamente, reduziram entre 60 e $70 \%$ a densidade do $U$. plantaginea na cultura do milho, aos 35 dias após a aplicação (Spader e Vidal, 2000). Em outro estudo, reduziu-se $98 \%$ da infestação da espécie Setaria viridis no feijoeiro com a aplicação de $0,6 \mathrm{~kg} \mathrm{ha}^{-1}$ de trifluralin na condição de pré-emergência (Soltani et al., 2010). Também se constatou redução da infestação de $U$. plantaginea e Digitaria sanguinalis na cultura do feijão através do uso de herbicidas residuais (Lamego et al., 2011). Estas pesquisas indicam ser possível reduzir a interferência imposta pelas infestantes e incrementar o desempenho agronômico do feijoeiro com a utilização adequada destes produtos.

Tabela 4. Rendimento de grãos da cultura do feijão em função do efeito de dois cultivares de feijão, quatro herbicidas residuais e duas doses. Eldorado do Sul, RS, 2008/09.

\begin{tabular}{|c|c|c|c|c|}
\hline \multirow{3}{*}{ Tratamentos } & \multicolumn{4}{|c|}{ Rendimento de grãos $\left(\mathrm{kg} \mathrm{ha}^{-1}\right)$} \\
\hline & \multicolumn{2}{|c|}{ IPR Graúna } & \multicolumn{2}{|c|}{ UTF-06 } \\
\hline & Dose $100 \%$ & Dose $120 \%$ & Dose $100 \%$ & Dose $120 \%$ \\
\hline Dimethenamid & $\mathrm{R}^{*} 566 \mathrm{aD}^{(1)}$ & $\mathrm{U}{ }^{*} 475^{*} \mathrm{bC}$ & $\mathrm{R}{ }^{*} 640^{*} \mathrm{bC}$ & $\mathrm{T}{ }^{*} 978^{*} \mathrm{aB}$ \\
\hline S-metolachlor & $\mathrm{R}^{*} 745^{*} \mathrm{bC}$ & $\mathrm{T}^{*} 1.026^{*} \mathrm{aB}$ & $\mathrm{R}{ }^{*} 743^{*} \mathrm{bB}$ & $\mathrm{T}^{*} 1.054^{*} \mathrm{aB}$ \\
\hline Pendimethalin & $\mathrm{R} * 860^{*} \mathrm{bB}$ & $\mathrm{T}^{*} 1.216^{*} \mathrm{aA}$ & $\mathrm{S} \quad * 338 * \mathrm{aD}$ & $\mathrm{U}^{*} 333^{*} \mathrm{aC}$ \\
\hline Trifluralin & $\mathrm{R} * 1.421^{*} \mathrm{aA}$ & $\mathrm{U}^{*} 1.164^{*} \mathrm{bA}$ & $\mathrm{R} * 1.385^{*} \mathrm{aA}$ & $\mathrm{T}^{*} 1.374^{*} \mathrm{aA}$ \\
\hline Test. sem controle & \multicolumn{2}{|c|}{$* 384$} & \multicolumn{2}{|c|}{$* 101$} \\
\hline Test. com controle & \multicolumn{2}{|c|}{$2.619 *(2)$} & \multicolumn{2}{|c|}{$1.710^{*}$} \\
\hline C. $\mathrm{V}^{(3)}(\%)$ & \multicolumn{4}{|c|}{18} \\
\hline $\operatorname{DMS}^{(4)}(\mathrm{A})(\%)$ & \multicolumn{4}{|c|}{137} \\
\hline DMS (B) $(\%)$ & \multicolumn{4}{|c|}{94} \\
\hline DMS (C) (\%) & \multicolumn{4}{|c|}{194} \\
\hline DMS (D) (\%) & \multicolumn{4}{|c|}{275} \\
\hline DMS (E) $(\%)$ & \multicolumn{2}{|c|}{242} & \multicolumn{2}{|c|}{274} \\
\hline \multicolumn{5}{|c|}{$\begin{array}{l}\text { (1) Médias com letras distintas diferem entre si pelo teste } \mathrm{t}(\mathrm{p}<0,05) \text {, sendo que letras minúsculas a direita }(\mathrm{a}, \mathrm{b}) \\
\text { comparam médias de doses de um mesmo herbicida, em uma mesma cultivar; letras maiúsculas a direita }(\mathrm{A}, \mathrm{B}, \mathrm{C}) \\
\text { comparam médias de herbicidas em uma mesma dose, em uma mesma cultivar; e, letras maiúsculas a esquerda }(\mathrm{R}, \mathrm{S} \\
\text { e T, U) comparam médias de herbicidas em uma mesma dose, em cultivares diferentes. }{ }^{(2)} \text { Asterisco ao lado direito dos } \\
\text { valores significa diferença significativa ( } \mathrm{p}<0,05) \text { em relação à testemunha sem controle e asterisco ao lado esquerdo } \\
\text { indica diferença significativa ( }<0,05) \text { em relação à testemunha com controle. }{ }^{(3)} \text { Coeficiente de variação do conjunto } \\
\text { de dados obtido na análise de variância. }{ }^{(4)} \text { Diferença mínima significativa para comparar médias de: (A) doses de um } \\
\text { mesmo herbicida, num mesmo cultivar; (B) herbicidas em uma mesma dose, num mesmo cultivar; (C) doses de um } \\
\text { herbicida em cultivares diferentes; (D) quaisquer cultivares, herbicidas e doses; e, (E) herbicidas em uma mesma dose } \\
\text { com as testemunhas sem ou com controle, num mesmo cultivar. }\end{array}$} \\
\hline
\end{tabular}

A atividade residual dos herbicidas não foi longa o suficiente para evitar perdas da produtividade da cultura. As diferenças na eficácia entre os herbicidas podem ser atribuídas as características físicas e químicas específicas de cada produto e que lhes permitem persistir no solo por certos períodos de tempo. Tais características incluem, em especial, os valores da solubilidade em água e da partição octanol:água, que influenciam os processos de dissipação destes compostos no ambiente. Além disso, outros fatores, como as condições ambientais, os atributos do solo e o manejo da cultura, entre outros, afetam a dinâmica de herbicidas no solo (Inoue et al., 2011). Deste modo, a interação destes fatores pode favorecer 
mais a persistência de alguns herbicidas em relação aos demais, o que acarreta em maior atividade residual no solo sobre as infestantes.

Cultivares competitivas e herbicidas residuais podem contribuir para os programas de MIPd em feijão porque reduzem a infestação das infestantes durante o período crítico de interferência. Além disto, as plantas daninhas que emergem nas áreas tratadas têm crescimento atrasado (Lamego et al., 2011), o que reduz o seu impacto na cultura e facilita as ações de controle em pós-emergência. No entanto, para se obter sucesso na redução da infestação do $U$. plantaginea com herbicidas residuais, devem-se combinar as ações de manejo em pré e pós-emergência da cultura do feijão.

Nesse trabalho, a cv. UTF-06 foi mais competitiva com o papuã do que a cv. IPR Graúna, mas, o rendimento de grãos obtido com IPR Graúna foi muito superior ao de UTF-06 (Tabela 4). Ou seja, além das características morfofisiológicas analisadas aqui, o potencial de rendimento e a capacidade de adaptação do cultivar ao ambiente precisa ser levado em consideração no MIPd para o sucesso agronômico da lavoura.

\section{Conclusões}

Herbicidas residuais na condição de préemergência do feijoeiro reduziram o nível de infestação de $U$. plantaginea durante o período crítico de interferência e incrementaram a produtividade de grãos da cultura em comparação à testemunha infestada.

$\mathrm{O}$ herbicida trifluralin teve maiores níveis de redução da infestação dessa planta daninha e de acréscimo no desempenho da cultura do que S-metolachlor, dimethenamid e pendimethalin. O cv. de feijão UTF-06, de ciclo curto e porte ereto, foi mais competitivo com $U$. plantaginea do que IPR Graúna.

A aplicação somente dos herbicidas residuais em pré-emergência não foi suficiente para controlar totalmente U. plantaginea e garantir a mesma produtividade da cultura na condição sem interferência dessa infestante.

\section{Agradecimentos}

Os autores agradecem ao CNPQ e à CAPES pelo apoio à pesquisa.

\section{Referências}

ANDRADE, C.A.B. et al. Efeito da competição com plantas daninhas em diferentes espaçamentos sobre o rendimento de três cultivares de feijão (Phaseolus vulgaris L.). Ciência e Agrotecnologia, v.23, n.3, p.529539, 1999.

BARROSO, A.A.M. et al. Interferência entre espécies de planta daninha e dois cultivares de feijoeiro em duas épocas de semeadura. Bragantia, v.69, n.3, p.609-616, 2010.

BLACKSHAW, R.E. et al. Integration of cropping practices and herbicides improves weed management in dry bean (Phaseolus vulgaris). Weed Technology, v.14, n.2, p.327336, 2000.

CAMPOS, H. Estatística aplicada à experimentação com cana-de-açúcar. Piracicaba: ESALQ, 1984. 292p.

COBUCCI, T. Manejo e controle de plantas daninhas em feijão. In: VARGAS, L.; ROMAN, E.S. (Org.). Manual de manejo e controle de plantas daninhas. Bento Gonçalves: Embrapa Uva e Vinho, 2008. p.453-480.

GEPTS, P.; FERNÁNDEZ, F. Etapas de desarrollo de la planta de fríjol común (Phaseolus vulgaris L.). Cali: CIAT, 1982. 10p.

INOUE, M.H. et al. Efeito residual de herbicidas aplicados em pré-emergência em diferentes solos. Planta Daninha, v. 29, n.2, p.429-435, 2011.

INSTITUTO BRASILEIRO DE GEOGRAFIA E ESTATISTICA - IBGE. Banco de Dados Agregados - 2015. Disponível em 
<http://www.sidra.ibge.gov.br>. Acesso em 15/07/15.

LAMEGO, F.P. et al. Seletividade dos herbicidas S-metolachlor e alachlor para o feijão-carioca. Planta Daninha, v.29, n.4, p.877-883, 2011.

MINISTERIO DA AGRICULTURA, PECUARIA E ABASTECIMENTO - MAPA. Sistema de Agrotóxicos Fitossanitários (Agrofit). Disponível em: <http://agrofit.agricultura.gov.br/primeira_pagi na/extranet/AGROFIT.html>. Acesso em: 03/03/2014.

\section{NOGUEIRA, M.C.S. Estatística experimental} aplicada à experimentação agrícola. Piracicaba: USP-ESALQ, 1997. 250 p.

NUNES, A.L. et al. Manejo integrado de plantas daninhas na cultura do milho. Bragantia, v.69, n.2, p.299-304, 2010.

SOLTANI, N. et al. Weed control, environmental impact and profitability with trifluralin plus reduced doses of imazethapyr in dry bean. Crop Protection, v.29, n.4, p.364368, 2010.

SPADER, V.; VIDAL, R.A. Eficácia de herbicidas graminicidas aplicados em préemergência no sistema de semeadura direta do milho. Planta Daninha, v.18, n.2, p.373-380, 2000.

STRECK, E.V. et al. Solos do Rio Grande do Sul. Porto Alegre: Emater/RS - UFRGS, 2008. $222 \mathrm{p}$.

TEIXEIRA, I.R. et al. Competição entre feijoeiros e plantas daninhas em função do tipo de crescimento dos cultivares. Planta Daninha, v.27, n.2, p.235-240, 2009.

VIDAL, R.A. et al. Interferência e nível de dano econômico de Brachiaria plantaginea e Ipomoea nil na cultura do feijão comum. Ciência Rural, v.40, n.8, p.1675-1681, 2010. 